gioso, la Iglesia prefiriera volver al cultismo ázimo, único término usado hoy.

Tulane University.

Thomas Montgomery

\title{
LAS PRIMERAS GLASIFICACIONES TRIPARTITAS DE LAS PARTES DE LA ORAGIÓN: VILLALÓN Y EL BROCENSE
}

Platón, como es bien sabido, opinó que los elementos constitutivos de la oración eran dos: el nombre y el verbo. A ellos añadió Aristóteles otro más: la conjunción (nexo, "partícula") ${ }^{1}$. Esta división aristotélica de la oración, en tres partes, reapareció durante el Renacimiento en los tratados gramaticales de Francisco Sánchez de las Brozas $^{2}$. Hasta qué punto influyó el Brocense sobre la doctrina gramatical española en lo relativo a la clasificación de las partes de la oración, es lo que me propongo indagar en el presente estudio ${ }^{3}$.

Hasta mediados del siglo xvi, la única gramática de la lengua vulgar que hubo en España fue la de Antonio de Nebrija ${ }^{4}$. Si tenemos en cuenta que en sus tiempos reinaba sin discusión la doctrina gramatical de Dionisio de Tracia, el cual, echando mano de una mezcla de criterios (la forma, la función, el significado y la colocación), había distinguido ocho partes de la oración ${ }^{5}$, fuerza es reconocer que las ideas de Nebrija, notablemente lúcidas y coherentes, constituyen ya una primera desviación respecto de los conceptos tradicionales.

1 Cf. R. H. Ronins, Ancient and mediaeval grammatical theory in Europe, London, 1951, pp. 23 ss.

2 Véase Constantino García, Contribución a la historia de los conceptos gramaticales: la aportación del Brocense, Madrid, 1960, donde se hace un análisis detallado de la doctrina gramatical de este humanista.

3 No resulta fácil determinar por qué razones se resucitaron las ideas de la división tripartita de la oración. Es posible que no se trate exclusivamente de un eco de la antigua clasificación griega, y que haya que tomar en cuenta también la influencia de los gramáticos árabes y hebreos. Me parece, pues, demasiado tajante la afirmación de C. GARcía, op. cit., p. 82: "No creemos... que exista influencia alguna ni de la Gramática árabe ni de la hebrea". Sobre la relación entre las clasificaciones tripartitas de griegos, hebreos y árabes, véase THEodor BENFEY, Geschichte der Sprachwissenschaft und orientalischen Philologie in Deutschland seit dem An. fange des 19. Jahrhunderts, mit einem Rückblick auf die früheren Zeiten, München, 1869, pp. 186 ss.; ERNEST RENAN, Histoire générale et système comparé des langues sémitiques, Paris, 1863, pp. 376 ss.; S. Munk, "Notice sur Abou'l-Walid Merwan Ibn-Djana'h et sur quelques autres grammariens hébreux du xe et du xie siècle", $J A, 4 \mathrm{e}$ série, 15 (1850), 297-338; 16 (1851), 5-50, 201-252.

4 Sobre la división nebrisense de la oración en diez partes, cf. JUdith SENIor, "Dos notas sobre Nebrija", NRFH, 13 (1959), 83-88.

5 Puede verse un análisis de la famosa clasificación de Dionisio de Tracia en Berthold Delbrück, Vergleichende Syntax der indogermanischen Sprachen, 1. Teil, apud Karl Brugmann und Berthold Delbrück, Grundriss der vergleichenden Grammatik der indogermanischen Sprachen, 3. Band, Strassburg, 1893. 
En 1558 publicó Cristóbal de Villalón su Gramática castellana ${ }^{6}$, primera gramática de una lengua europea vulgar que propone la división tripartita de las partes de la oración: "Acerca del castellano - dice ${ }^{7}$-, tres partes principales hallo que son las que constituyen y componen la oraçión: nombre y verbo y artículos", y añade que "artículos" es el nombre que da "a todas aquellas diçiones y vocablos que el Latino llama indeclinables". En seguida toma Villalón las definiciones tradicionales de nombre y verbo y cuidadosamente elimina de ellas todo cuanto no se refiere estrictamente al significado. Define así el nombre como "una voz o vocablo que sinifica las cosas propia o comúnmente, y no sinifica hazer ni padecer en tiempo" (p. 245), y el verbo como "una boz que sinifica hazer o padecer (que llama el Latino actión o passión) alguna obra en alguna differencia de tiempo" (p. 248). Sin embargo, en su definición de los "artículos", Villalón no sigue este criterio semántico, sino que, repitiendo la doctrina tradicional, agrupa la preposición, el adverbio, la conjunción y la interjección sobre la base morfológica de su indeclinabilidad ${ }^{8}$. De todos modos, contando estos "artículos" como cuatro partes de la oración, Villalón no habla ya de ocho partes, sino sólo de seis ${ }^{9}$ incluye el pronombre dentro de la categoría del nombre, y al participio (mencionado de pasada al hablar de la voz pasiva) lo llama "nombre verbal". El criterio para definir estas dos subcategorías es, por cierto, exclusivamente semántico ${ }^{10}$.

6 La única gramática que precedió a la de Villalón es la anónima de Lovaina, 1555: Útil y breve institutión para aprender los principios y fundamentos de la lengua hespañola.

7 Apud CONDE DE LA ViñazA, Biblioteca histórica de la filologia castellana, Madrid, 1893, p. 245. (En esta y en las demás citas desarrollo las abreviaturas y modernizo la puntuación, la acentuación y el uso de las mayúsculas).

s LA Viñaza, pp. 250 ss.: “...es de saber que la lengua castellana tiene palabras que el latino llama preposiciones, porque se proponen al nombre o al verbo en la cláusula, para manifestar más el affecto humano del que la pronunçia... Ay otras palabras o vocablos en la lengua castellana que el latino llama aduerbios, porque añadidos al verbo añaden, engrandeçen o desminuyen la sinificaçión en la cláusula castellana en que se ponen... Ay otras palabras en la lengua castellana que el latino llama interjeçiones, porque son vnas bozes que pronunciadas denotan el affecto interior del alma... Ay otras palabras en la lengua castellana que el latino llama conjunciones, porque ayuntan y ligan vna diçión con otra en la cláusula en que se ponen".

9 Cuando los gramáticos romanos adoptaron la clasificación de Dionisio, se vieron obligados a modificarla un tanto. Entre las ocho partes griegas figuraba el artículo, forma inexistente en latín; para mantener el mismo número, añadieron la interjección, que los griegos habían considerado como una clase de adverbio. Véase un estudio detallado sobre los gramáticos latinos de la época clásica y de la primera Edad Media en J. Golling, Einleitung in die Geschichte der lateinischen Syntax, hrsg. von Gustav Landgraf (Historische Grammatik der lateinischen Sprache, 3. Band), Leipzig, 1903.

10 "Pronombre es una diçión o vocablo castellano que se pone en lugar del nombre propio, como estos vocablos: yo, tú aquél. Estos vocablos, y semejantes, por sf ninguna cosa sinifican más de aquella que mostraren o fuere la intinçión del que la pronuncia señalar, o mostrar, o entender por ella" (LA ViÑAzA, p. -247) A propósito de las formas soy amado, soy herido, etc.: "Ia passion que importan los verbos activos... no se puede espresar, declarar ni manifestar sino por circunlo- 
Con esta clasificación que acabo de exponer, Villalón se anticipó al Brocense, en cuya Minerva - destinada a una difusión mucho más amplia que la Gramática de su predecesor- figura también la división tripartita en nombre, verbo y partículas ${ }^{11}$. Tanto el pronombre como el participio se clasifican asimismo dentro de la categoría del nombre ${ }^{12}$. Pero hay dos diferencias importantes que separan esta clasificación de la de Villalón: para el Brocense, la interjección no es parte del discurso. Dice: "Interiectionem Graeci adverbiis annumerant, sed falso: nam neque voces Latinae aut Graecae sunt, etiam si Latinis aut Graecis literis scribantur, sed signa tristitiae aut laetitiae, qualia in auibus aut quadrupedibus, quibus tamen nec vocem nec orationem concedimus. Vide adagium $N e$ my quidem, \& Ne gry quidem: Valla, lib. 2, cap. 11" (I, 2). Y, lo que es más importante, su criterio clasificatorio es completamente distinto del de Villalón. En vez de servirse de razonamientos semánticos, el Brocense atiende tan sólo a consideraciones morfológicas. Define así el nombre como "[vox] numeri casualis cum genere" (I, 5), y el verbo como "vox particeps numeri personalis cum tempore" $(\mathbf{I}, 12)^{13}$.

A pesar de la influencia que la mayor parte de las ideas del Brocense ejerció en la doctrina gramatical española, su clasificación tri-

quio deste verbo soy, mediante vn nombre verbal que espresa o importa la sinificaçión del verbo, como amado, herido, açotado; y semejantes vocablos... son propiamente nombres verbales, porque importan y espresan la sinificaçión de sus verbos amo, hiero, açoto" (ibid., p. 249).

11 Minerva, seu de causis linguae Latinae commentarius..., editio septima, Amstelaedami, 1807, lib. I, cap. 2: "Cum igitur oratio sit finis grammatici, excutiamus ex quibus haec oratio possit constitui, ita ut nihil sit quod per orationem non possimus enunciare. Sunt autem haec tria, nomen, verbum, particulae. Nam apud Hebraeos tres sunt partes orationis, nomen, verbum \& dictio consignificans. Arabes quoque has tantum tres orationis partes habent: pheal, verbum; ismi, nomen; herph, dictionem: quas tres partes orationis omnes linguae Orientales habent. Rabbinus ille, qui contra Cosdram regem Persarum disputat, omnes linguas ab Hebraica originem duxisse contendit, \& Graccam \& Latinam ohm tantum tres orationis partes habuisse. Idem sentit Plutarchus in Quaestion. Platonicis; \& D. Augustinus in Categoriis ex Aristotelis sententia tres partes orationis constituit".

12 C. García, op. cit., pp. 76 ss, y 131 ss., expone detalladamente las ideas del Brocense en cuanto al pronombre y el participio.

13 Sus definiciones del adverbio, la conjunción y la preposición son más tradicionales, y se basan primordialmente en la forma y la función de dichas categorias: "Praepositio est vox expers numeri, quae casibus praeponitur et in compositione reperitur" (III, 12) . "Aduerbium videtur dici quasi "ad verbum», quia verbis, velut adiectiuum, adhaeret, ut bene dormit...; et est proprius modus in verbis... Iunguntur et aduerbia aliis partibus" (III, 13). "Coniunctio neque casus, neque alias partes orationis, vt imperiti docent, coniungit: ipsae enim partes inter se coniunguntur, vt nomen nomini, nomen verbo, \&c. Sed coniunctio orationes inter se coniungit" (III, 14). - Estas definiciones se ajustan perfectamente a la filosofía gramatical del Brocense, según la cual forma y función son lo único que incumbe a la gramática: "Grammatica est ars recte loquendi, cujus finis est congruens oratio... Mihi perfectus absolutusque grammaticus est ille qui in Ciceronis vel Vergilii libris intelligit quae dictio sit nomen, quae verbum, \& caetera, quae ad solam Grammaticam spectant, etiamsi sensum verborum non intellegat: est enim oratorum \& poetarum lectio variis artibus referta, quas si magister iste callet, jam non grammaticus dicendus est, sed dum explanat Astrologiam, astrologus; dum Historiam, historicus; dum praecepta Eloquentiae, rhetor" (I, 2). 
partita de las partes de la oración no fue adoptada sino por dos gramáticos del primer tercio del siglo xvn, los cuales la fundan asimismo en consideraciones morfológicas: Bartolomé Jiménez Patón y Gonzalo Correas $^{14}$.

Dice Jiménez Patón en sus Instituciones de la gramática española (1614) : "Varrón señaló dos partes solas, y parece lo tomó de Aristóteles, aunque después, siguiendo el parecer de Dión, dixo que eran tres, y en esto no tuuo constancia, pues vltimamente señaló quatro. Aristarco afirmó que eran once. $Y$ assí lo sintió Quintiliano, aunque después puso ocho. Pedro Simón Abril en su Arte latina y griega puso diez. Antonio de Nebrixa enseñó ocho, y ésta es la opinión que más fuerça a tenido y durado. Francisco Sánchez de las Broças prueua que son seis. Mi opinión (dende que tuue discurso propio) a sido de que son cinco"15. Esta discrepancia con el Brocense es sólo aparente. Es cierto que, en varias ocasiones, se dice en la Minerva que las partes de la oración son seis: "voces numeri participes sunt nomen, verbum, participium; expertis numeri praepositio, adverbium, conjunctio: quae partes orationis appellantur"; pero luego aclara, no sin ciertas vacilaciones, que el participio ha de considerarse más bien como nombre verbal $^{16}$, de tal manera que su clasificación coincide con la de Jiménez Patón: nombre, verbo, preposición, adverbio y conjunción. Jiménez Patón nunca expone categóricamente una clasificación tripartita, pero, en vista de su dependencia respecto del Brocense, es muy probable que él también considerara la preposición, el adverbio y la conjunción como miembros de una sola categoría de "artículos"17.

Jiménez Patón basa sus definiciones del nombre y del verbo en razones morfológicas: "El nombre (en lengua española) no se declina por casos, sino se varía con preposiciones, como el ombre, del ombre, para el ombre. El verbo se conjuga por modos y tiempos, como amo,

14 Los gramáticos españoles más tardios prefirieron atenerse a la clasificación tradicional: nombre, verbo, pronombre, participio, adverbio, conjunción, preposición e interjección: y añadieron una novena parte: el artículo. Cf. Louis KuKENHEIM, Comtributions a l'histoire de la grammaire italienne, espagnole et française à l'époque de la Renaissance, Amsterdam, 1932, pp. 116 ss.

15 Edición de Baeza, 1621 (junto con el Mercurius trimegistus, sive de triplici eloquentia sacra), p. 166.

10 Cf. sobre esto C. García, op. cit., pp. 81 y 131.

17 Las definiciones de estas tres partes son, una vez más, las que ya conocemos, basadas principalmente en la forma y la función. "El aduerbio es al que el nombre o verbo le da calidad buena o mala... La conjunción junta semejantes oraciones... La preposición se pone al nombre por aposición, y no por composición como en el latín" (pp. 166 ss.). - Cuando Jiménez Patón se niega a considerar la interjección como categoría per se, su razonamiento es, en gran medida, simple traducción del de Francisco Sánchez (cf. supra el texto "Interiectionem Graeci..."): "Los griegos contaron entre sus aduerbios las interjeciones, mas fue engaño, porque ni son voces griegas ni latinas ni españolas, aunque se escriban con sus letras. Las quales no son más de vnas señales de alegría o de pesar que se hallan en los brutos, que ni tienen discurso ni habla. Por estas causas Lorenço Vala desechó la interjeción de las partes de la oración. An replicado algunos que basta hacerle mudar el sentido a la oración para que sea parte suya; a los quales e respondido que vna puntuación desta o de aquella manera causa esta variedad de sentido, y no por eso los puntos son parte de la oración" (p. 173). 
amaba, amé" (p. 166). Páginas después, sin embargo, dando muestras de gran vacilación, se sirve de razonamientos semánticos para demostrar que el nombre y el participio no son sino nombres ${ }^{18}$.

Si la dependencia de Jiménez Patón respecto del Brocense es indiscutible, otro tanto se puede decir del Arte de la lengua española castellana de Gonzalo Correas, obra escrita en 1623. Correas declara que las partes de la oración son tres, se apoya para ello en consideraciones morfológicas, e incluye el pronombre y el participio dentro de la categoría del nombre: "Conozerá el nonbre en que tiene singular i plural, i demás deso, en latín i griego, en que se declina por casos; el verbo, en que se conxuga i varía por personas i tiempos de singular i plural en todas las lenguas; i la partícula, en que es invariable en todas" ${ }^{19}$. Pero, al igual que Jiménez Patón, se muestra muy vacilante en su método de análisis, pues en otros lugares de su Arte modifica las definiciones, incurriendo en la consabida mezcla de razonamientos semánticos y formales ${ }^{20}$. En su interpretación de las interjecciones adopta simplemente el pensamiento tradicional: la interjección -dice- no es un signo extragramatical, sino una clase especial de las partículas ${ }^{21}$.

18 "El participio no hace distinta parte de la oración que el nombre, porque es cierta manera de nombre verbal adjetiuo, y si por alguna causa auía de ser parte distinta, fuera por su sinificar con tiempo; no sinifica, luego no es. Porque amans en latín, y amante en español, puede ser de todos tiempos... El pronombre también no constituye distinta parte de la oración que el nombre, porque si lo fuera, tuuiera difinición particular que declarara su naturaleça, y no le conuiniera la que le dan al nombre, como le conuiene v quadra; luego también es nombre, porque se declina por casos y no sinifica con tiempo" (pp. 169 ss.).

19 Ed. de Emilio Alarcos García, Madrid, 1954, p. 135 (fol. 59v). Al igual que Jiménez Patón, también Correas traduce pasajes de la Minerva y los incorpora en su Arte. Así, el comentario del Arte sobre las divisiones tripartitas en general no es sino una traducción del pasaje que he transcrito supra, nota 11: "Son, pues, las partes de la orazión tres: nonbre, verbo, partícula. $O$, por más claro hablar, las palavras de una lengua, sea cualquiera, son tres: porque todos los vocablos son en tres maneras, $\mathrm{i}$ se dividen en tres partes o montones, i se rreduzen a estos tres xéneros dichos, nonbre, verbo i partícula, como está llano i asentado en hebreo, caldeo i arávigo $i$ en todas las otras lenguas orientales $i$ de Africa, $i$ todas las del mundo convienen en esto; i era ansí claro i asentado antiguamente en griego i latín, como lo rrefiere Juan Isaak en su Arte hebrea del otro Rrabino que dize, en el libro que escrivió contra el rrei Cosdroas, que antes en griego i latín no avía más de tres partes de orazión. Dixo lo mesmo Varrón por sendenzia [sic] de Dión, aunque disputa otros números i no se afirma; tocólo Quintiliano; i Plutarco siente que son tres, en las Questiones de Platón; i San Agustín por parezer de Aristóteles lo saca, i pone tres en las Categorias" (ed. cit., pp. 133-134 [fol. 59r]).

20 "Nonbre es aquella palavra i boz con que se nonbra cada cosa, i tiene xéneros, artículos, números, casos o diferenzia de casos con preposiziones" (p. 139 [fol. 60v]). "Verbo es aquella palavra que sinifica el hazer i obrar i dezir las cosas, i ser hechas i obradas i dezirse; i tiene boz i conxugazión" (p. 240 [fol. 98r]) . "La partícula, terzera i última parte de la orazión, es aquella palavra que nunca se varía por números ni cadenzias, sino que sienpre se dize de una manera invariable, para sinificar alguna zircunstanzia en la orazión contenida en su sinificazión" (p. 333 [fol, 122v]).

21 Los lingüistas modernos parecen estar de acuerdo con el Brocense, ya que no suelen contar la interjección como parte de la oración. Cf. J. WAckernaget, Vorlesungen über Syntax mit besonderer Berücksichtigung von Griechisch, Lateinisch und Deutsch, Basel, 1920, p. 70: "Wir unserseits werden zunächst die sogen. Interjektion 
Aunque en la actualidad es ampliamente conocida la división tripartita de la oración expuesta por el Brocense, las ideas de Villalón han permanecido casi ignoradas, a pesar de que fue él quien por primera vez estableció esa división en el Renacimiento. Cierto que la clasificación de las partes del discurso basada en razonamientos semánticos no ha tenido mucha fortuna, pero a Villalón le corresponde el mérito de haber sido el primer gramático europeo moderno que estableció la división tripartita de la frase, incluyendo el pronombre y el participio dentro de la categoría gramatical del nombre ${ }^{22}$.

Hobart and William Smith Colleges.

JUDITH S. MERRILL

\section{LOS NIÑOS EN LA POESIA DE ANTONIO MACHADO *}

Como es bien sabido, el núcleo más esencial y central de la problemática de Antonio Machado es el tiempo. Y alrededor del tiempo -en sus diversas manifestaciones- se construye toda la circunstancia del autor. En palabras muy citadas y comentadas, don Antonio nos dice que "el poeta profesa, más o menos conscientemente, una metafísica existencialista, en la cual el tiempo alcanza un valor absoluto. Inquietud, angustia, temores, resignación, esperanza, impaciencia, que el poeta canta, son signos del tiempo y, al par, revelaciones del ser en la conciencia humana" 1 . A la luz de esta explicación podemos com-

ausscheiden, da sie an der Grenze von Wörtern und Nichtwörtern stehen"; William J. Entwistle, Aspects of language, London, 1953, p. 148, sostiene que la interjección no es una parte de la oración sino un equivalente de oración (pro sentence) con valor semántico equiparable al de una oración gramatical; Louss $\boldsymbol{H}$. Grax, Foundations of language, New York, 1939, p. 166, excluye asimismo la interjección, diciendo que unas veces es un mero "reflejo vocal" (como ¡Ay!) y otras una oración elíptica (;Cuidado! = "Tenga usted cuidado").

22 En los tratados modernos son muy frecuentes las clasificaciones tripartitas. W. J. Entwistle, op. cit., cap. 7, fundándose en una mezcla de criterios que atienden a la forma, la función, el significado y la predicación lógica, divide las partes de la oración en nombre (sustantivo, adjetivo, adverbio, numeral, pronombre, infinitivo, participio), verbo y particula (conjunción y preposición). L. H. GRAY, op. cit., cap. 6, dice: "We must seek to classify them [las partes de la oración] according to form, i. e. according to morphology viewed in the light of historical development", y a continuación reclabora la clasificación bipartita (nombre y verbo), agrupando el sustantivo, el adjetivo, el adverbio, la preposición, la conjunción y el pronombre bajo la categoría del nombre. Cf. también J. WaCkfrnagel, op. cit., p. 70: "Innerhalb der eigentlichen Wörter gibt es die zwei Hauptgruppen der Nomina und Verba, der Wörter, welche Kasus haben, und der Wörter, welche die Personen des Subjekts unterscheiden, dazu als dritte Gruppe die flexionlosen Wörter".

* Trabajo lef́do, con algunas modificaciones, en el Symposium sobre literatura española contemporánea celebrado en la Universidad de McMaster (Hamilton, Ontario, Canadá) el 20 de marzo de 1965.

1 Explicación que Antonio Machado hizo de su propia poética, en 1932, para la antología de P'oesia española contemporánea compilada por Gerardo Diego. En la ed. de Madrid, 1959, que es la que utilizo, la cita se encuentra en la p. 153. 